\title{
SLOW-MOVING LANDSLIDE DAMAGE ASSESSMENT OF HISTORIC MASONRY CHURCHES: SOME CASE-STUDIES IN ITALY
}

\author{
CHIARA FERRERO ${ }^{1,2 *}$, LUDOVICA CAMBIAGGI ${ }^{1}$, ANDREA FENIALDI $^{1}$, PERE $^{2}$ \\ ROCA $^{2}$, RITA VECCHIATTINI ${ }^{3}$ AND CHIARA CALDERINI ${ }^{1}$ \\ ${ }^{1}$ Department of Civil, Chemical and Environmental Engineering \\ University of Genoa \\ Via Montallegro 1, 16145 Genoa, Italy \\ email: e-mail: chiara.ferrero@edu.unige.it, ludovica.cambiaggi@edu.unige.it, \\ andrea.fenialdi@gmail.com, chiara.calderini@unige.it (*corresponding author) \\ ${ }^{2}$ Department of Civil and Environmental Engineering \\ Technical University of Catalonia (UPC-BarcelonaTech) \\ Jordi Girona 1-3, 08034 Barcelona, Spain \\ e-mail: pere.roca.fabregat@upc.edu \\ ${ }^{3}$ Department of Architecture and Design, University of Genoa \\ Stradone S. Agostino 37, 16123 Genoa, Italy \\ e-mail: rvecchiattini@unige.it
}

Keywords: Historic churches, Masonry, Slow-moving landslides, Damage mechanisms.

\begin{abstract}
This paper presents a contribution for the damage assessment of historic masonry churches exposed to slow-moving landslides. In particular, the authors identified four global damage mechanisms, which are presented here by means of the critical damage assessment of four case studies located in the Liguria region (Italy) in areas affected by slow-moving landslides. For each church, a correlation between the damage patterns observed on-site and the ground movements induced by landslide phenomena was sought by means of visual inspections and crack interpretation. As a result, each damage mechanism was associated to a different pattern of ground movements produced by slow-moving landslides.
\end{abstract}

\section{INTRODUCTION}

Historic masonry churches are significant parts of world cultural heritage; thus, their conservation should be a primary goal for preservation engineers. Although these buildings may be potentially exposed to a number of natural (i.e. earthquakes, floods, landslides, etc.) and anthropic hazards (such as subsidence and tunneling), so far only the damage produced by seismic actions has been systematically investigated. Past and recent earthquakes showed in fact that historic masonry churches are particularly vulnerable to horizontal actions, which induce severe damage usually related to the out-of-plane collapse of building portions called macroelements $[2,3,4]$. In the last decades several studies were devoted to the damage and 
vulnerability assessment of historic masonry churches and led to the identification of their collapse mechanisms under seismic actions (e.g. $[3,4])$.

On the contrary, as described in [1], the response of historic masonry churches to soil displacements produced by phenomena like subsidence, foundation settlements and landslides has never been systematically analyzed. In particular, so far, in the literature attention was mainly paid to investigate the effects of vertical ground movements on single case studies (e.g. $[5,6])$. Conversely, the effects and damages induced to churches by phenomena like landslides, which produce a combination of both vertical and horizontal soil displacements [7], has not yet been explored.

With the aim to fill such a gap of information, the authors performed a damage survey campaign (described in detail in [1]) in 33 historic masonry churches located in the Liguria region (Italy) in areas affected by slow-moving landslides. Despite these latter are characterized by movement rates of the order of only some $\mathrm{mm} /$ year [8], severe and extensive damage congruent with the direction of slope movements was observed in several buildings of the sample, thus proving the vulnerability of historic masonry churches to slow-moving landslides. Some recurrent types of damage and damage mechanisms induced to churches by slow-moving landslides were also identified.

This paper presents the four global damage mechanisms identified in [1] by means of the critical damage assessment of four case studies chosen among the 33 churches considered. For each church, firstly, the damage pattern detected during on-site inspections was analyzed in detail and interpreted in terms of damage mechanisms. Then, all available data regarding landslide movements wet observed on-site. In this information about state almost no information horizontal). These latter
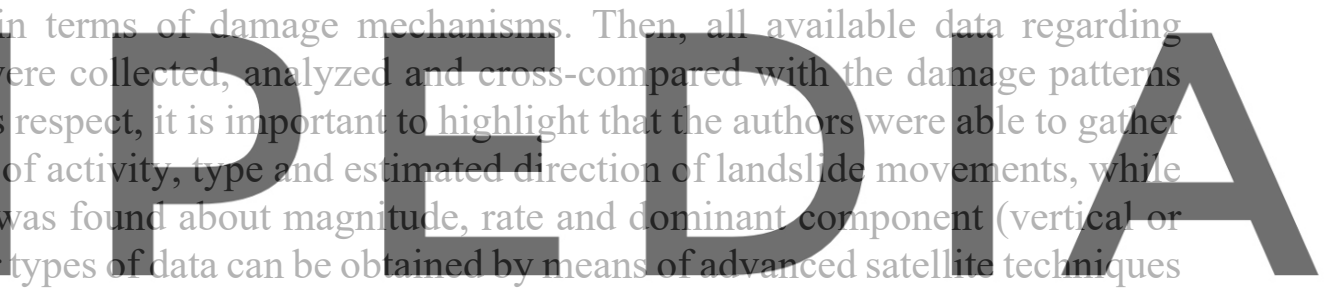

(such as the differential SAR interferometry [9]) or inclinometers, the latter providing a profile

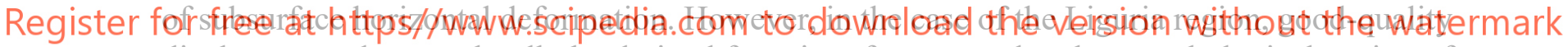
displacement data can hardly be derived from interferometry due the morphological setting of the territory, which consists primarily of mountainous and hilly areas covered in woods [10]. Furthermore, most of the landslide-affected areas have never been monitored by means of inclinometers. For these reasons, with the aim of coping with such a lack of information, in this paper cracks and deformations observed on-site were used as indicators of ground movements. As a result, the damage patterns corresponding to each damage mechanism could be attributed to specific soil displacement patterns produced by slow-moving landslides.

\section{DAMAGE MECHANISMS}

In general, the damage assessment presented in [1] proved that churches respond to slowmoving landslides with a global behavior where the different structural components (walls, arches, vaults, etc.) contribute jointly to accommodate soil displacements. This behavior is significantly different from the response by independent macroelements exhibited by churches under seismic actions.

In particular, the following four global damage mechanisms were identified (Figure 1): 
a. Hogging. This damage mechanism can be attributed to a concave-upward bending (hogging) of the structure produced by an incremental vertical ground movement in the direction of the longitudinal axis of the church (Figure 1a). The structure exhibits vertical cracks in longitudinal walls, repeated in each bay. Such cracks progress over the entire height of the wall, increasing in width with height, and continue up into arches and vaults, cutting them transversally. No significant cracks or gaps are observed in the floor.

b. Shear deformation. This damage mechanism can be attributed to a shear deformation of the structure produced by vertical ground movements along the longitudinal axis of the church (Figure 1b). Severe diagonal cracks propagating from the level of the ground are observed in longitudinal walls. A crack/gap in the floor can propagate between the cracks occurring in the opposite longitudinal walls.

c. Global rigid rotation. This mechanism is related to an incremental vertical ground movement along the transversal axis of the church (Figure 1c). Along this direction, the church is quite stiff and tends to rotate as a rigid body. There may be cracks, but the most relevant effects are (i) the out-of-plumb of longitudinal walls, (ii) the distortion of transverse arches, and (iii) the inclination of horizontal elements such as tie-rods, balustrades, steps and floors.

d. Extension. This mechanism is related to the horizontal component of landslide movement (Figure 1d). In this case, the structure exhibits multiple parallel diagonal cracks in vaults and floors, oriented in the same direction. In addition, severe vertical

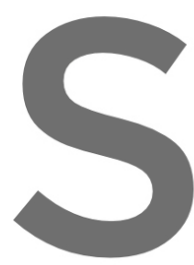
cracks occur in walls in planes perpendis propagate from the le
that these cracks prom floor to vaults, thus
entire height fion
the direction of the acting landslide.
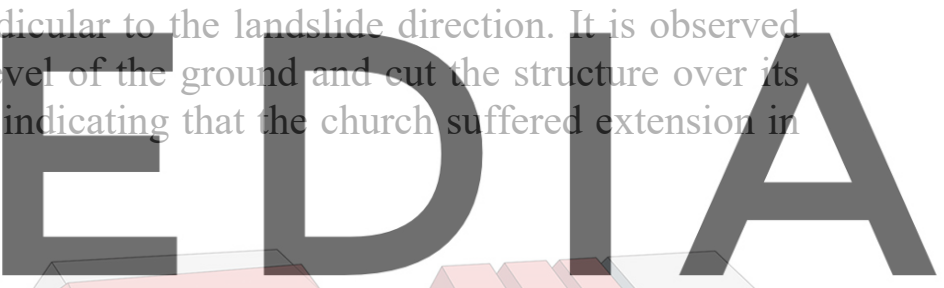

Register for free at https//www.scipedia.com to download the version without the watermark

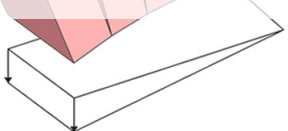

a)

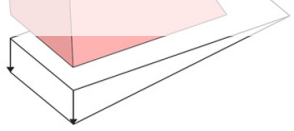

b)

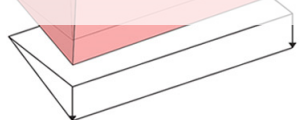

c)

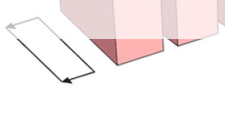

d)

Figure 1: Global damage mechanisms identified in [1]: a) Hogging, b) Shear deformation, c) Global rigid rotation, d) Extension.

It should be highlighted that various combinations of these mechanisms may occur in churches according to (i) the magnitude of vertical and horizontal soil displacements, (ii) the direction of the landslide movement with respect to the church axes, and (iii) the church geometry and structural configuration. Concerning this last point, it is worth noting that, given the same ground movement (an incremental vertical ground movement in the longitudinal direction of the church (Figure 1a-b), the occurrence of mechanism a) or b) may depend on the length/height ratio of longitudinal walls: mechanism a) prevails for high ratio (slender walls), mechanisms b) prevails for low ratio (squat walls). 


\section{CASE STUDIES}

This section presents the analysis of the four case studies under consideration, namely (i) San Martino church in Cembrano, (ii) San Bernardo da Mentone church in Ascona, (iii) San Lorenzo church in Sorbolo, and (iv) Santa Margherita church in Diano Arentino. These churches are representative examples, respectively, of the hogging, shear deformation, global rigid rotation, and extension mechanism. In the case of San Martino church in Cembrano, a combination between the hogging and extension mechanism was found.

For each church, this section provides a brief description of the main historical, geometric and constructive features as well as a detailed description of the crack patterns and deformations observed on-site. All the collected information about landslides movements as well as morphological setting of the soil are also reported. The data regarding landslide type, state of activity and estimated direction were derived from (i) the landslide maps of the basins plans of the Liguria region [11] [12], (ii) the Atlante dei Centri Abitati Instabili della Liguria (hereafter called Atlante [13]), and (iii) the maps of the Geoportale Nazionale (National Geo-portal) [14]. The contour curves of the slope were also considered in order to estimate landslide direction. Regarding landslide state of activity (active or dormant), it is important to point out that it is not relevant for the purposes of this work. Indeed, landslides that are currently classified as dormant were necessarily active at a certain point of their evolution over time. Thus, they could have caused the damage observed in the churches investigated.

With the aim of obtaining information about magnitude, rate and dominant component of landslide movement, by using the Geoportale Nazionale [14] the authors verified (i) the
availability of SAR data and (ii) the presence of inclinometers installed w thin the framework
of the REMOVER monitoring project of the Liguria region. However, regarding SAR datz,
quantitative displacernent dat useful for the purposes of this work could not be obtained.
Indeed, the churches under consideration are located in hilly and scarcely urbanized areas
characterized by low distributions of targeted ground points (used by satellites to acquire interferometric data) [10]. Furthermore, the information necessary to decompose into vertical

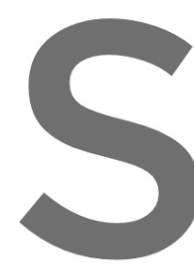

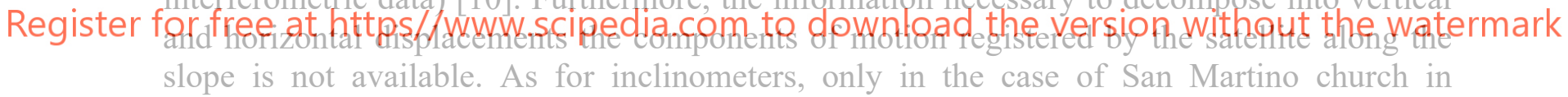
Cembrano, the landsiide-affected area surrounding the church has been monitored by means of inclinometers.

\subsection{San Martino church in Cembrano}

San Martino church is located in Cembrano in the municipality of Maissana (La Spezia province). The first documented information regarding the existence of Cembrano parish dates back to 1236; however, the exact date of construction of the church is unknown. In the nineteenth century some structural changes were performed: in particular, the left nave was added, and the original bell-tower was demolished and rebuilt. The masonry church, which is about $29 \mathrm{~m}$ and $14 \mathrm{~m}$ wide, consists of three naves with presbytery and semicircular apse. A triumphal arch separates the central nave from the presbytery. The central nave is covered by barrel vaults with lunettes, while the lateral naves present cross vaults and the presbytery is covered by a barrel vault. All the vaults are made of brick masonry.

The village of Cembrano as well as the church under consideration are located in a plan area surrounded by three dormant landslides (indicated as landslide LD1, LD2 and LD3 in Figure 
2a). In particular, the church is located at a distance of $68 \mathrm{~m}, 39 \mathrm{~m}$ and $125 \mathrm{~m}$ from landslides LD1, LD2 and LD3, respectively. Landslide LD3 was not considered for the purpose of this work since it is believed that it cannot affect the church due to its direction and distance from the building.

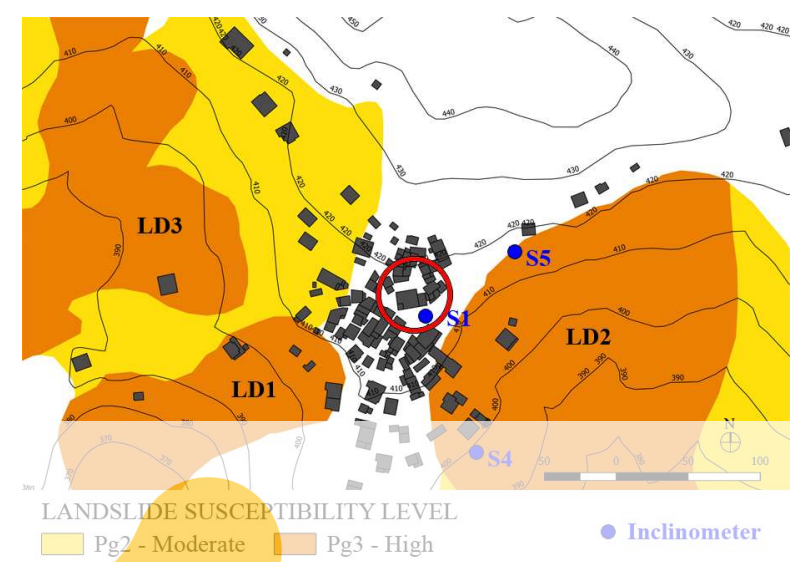

a)

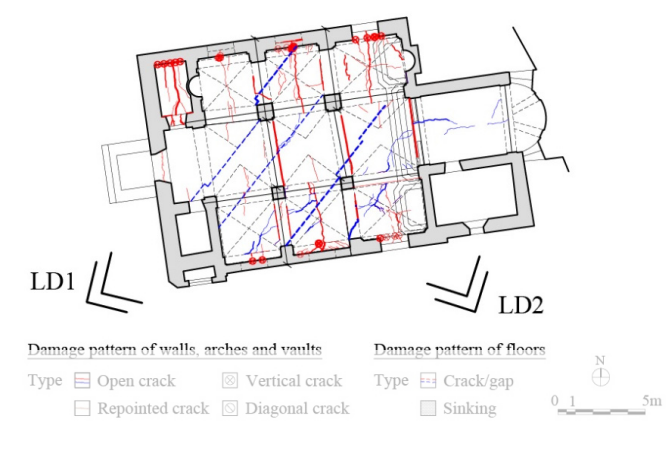

b)

Figure 2: San Martino church in Cembrano: a) position of the church and inclinometers on landslide maps, b) damage pattern.

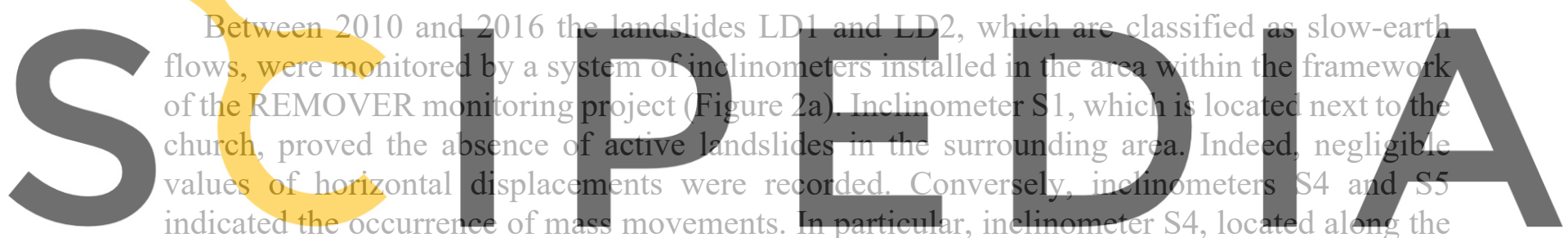

east flank of landslide LD2, recorded a displacement of about $6 \mathrm{~mm}$ in 6 year in the south-east

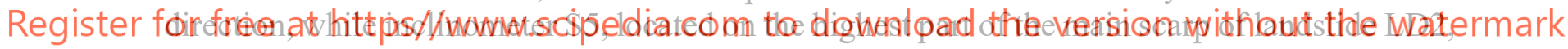
registered a displacement of about $56 \mathrm{~mm}$ in 6 year in the south direction.

The crack pattern surveyed in San Martino church is reported in Figure 2b. Extensive and severe damage is observed throughout the building. Significant cracks are present in the longitudinal walls in the middle of each bay (Figure 3a). In the first two bays behind the façade cracks are vertical, while in the third bay they exhibit a diagonal orientation up to the window and then they become vertical. These cracks progress along almost the entire height of the wall, increasing in width with height, and continue up into the arches and vaults above, cutting them transversally (Figure 3b). Conversely, no continuity is observed with the gaps of the floor. Since cracks propagate downwards with descending closure, such a crack pattern (colored in red in Figure $2 b$ ) can be associated with tensile stresses occurring in the upper walls due a concaveupward bending (hogging) of the structure along the longitudinal axis of the church. Such a hogging mechanism is consequence of incremental vertical ground movements in the longitudinal direction of the building. Since landslide LD1 moves in this direction, it is reasonable to assume that this one caused the observed hogging mechanism and corresponding crack pattern. 


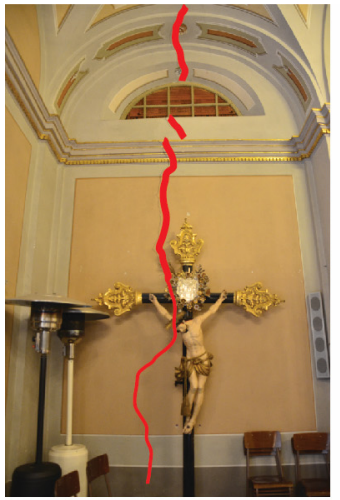

a)

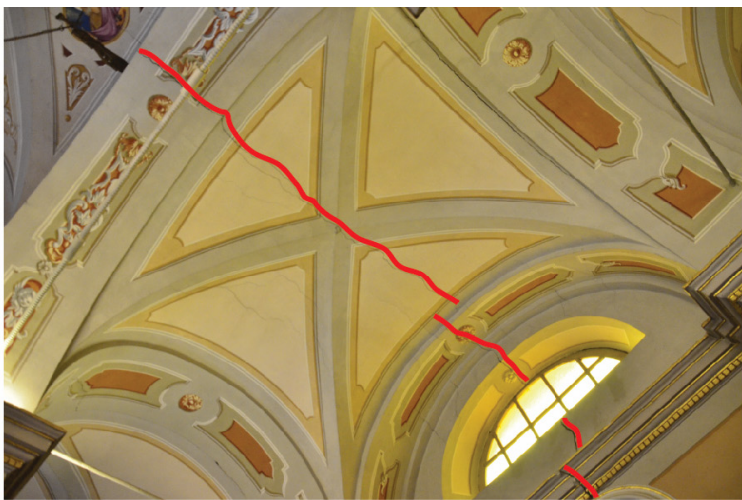

b)

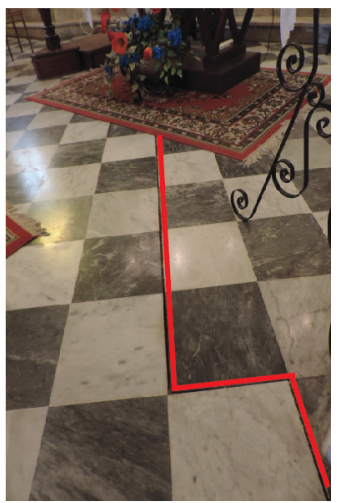

c)

Figure 3: Damage observed in San Martino church in Cembrano: a) vertical cracks in the longitudinal walls, b) cracks continuing up into arches and vaults, c) parallel oblique gaps in the floor.

In addition to the damage pattern described above, the presence of three parallel gaps (i.e. separations developing at the joints among tiles [1]) cutting diagonally the entire floor is observed (Figure 3c). Gap width ranges from $3 \mathrm{~mm}$ to $10 \mathrm{~mm}$, for a total of $24 \mathrm{~mm}$ along the entire length of the naves. Diagonal cracks are also observed in some vaults of the central and left nave, oriented in the same direction as the gaps of the floor. One of these cracks also continues into the barrel vault of the presbytery at mid-span. The horizontal separation among tiles, amounting in total to $24 \mathrm{~mm}$, suggests that the church was subjected to a horizontal movement in the direction perpendicular to the gaps of floors (an in Figure 2b, the latter correspond, to the direction of Consequently, the crack pattern shown in blue ir mechanism produced by conflict with the negligible vattes of horizon in Figure $2 \mathrm{~b}$ c
portant to higl
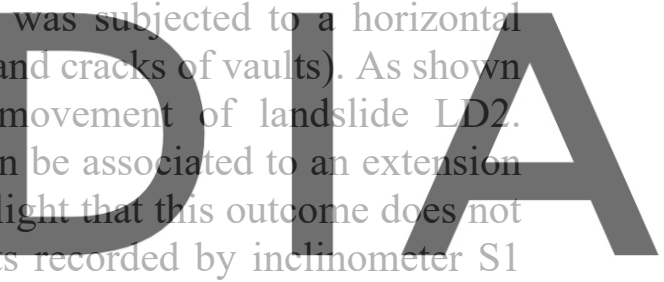
between 2010 and 2016. Indeed, the landslide was monitored for a very short time compared to

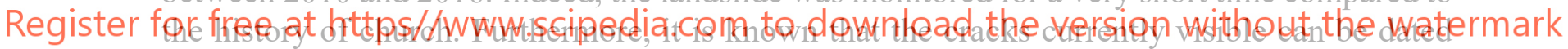
back at least to 2012, thus they probably occurred before the monitoring system was installed. On the other hand, the significant horizontal displacements measured by inclinometer S5 indicates that landslide LD2 is characterized by a significant component of horizontal movement, which is congruent with the crack pattern observed in the church.

\subsection{San Bernardo da Mentone church in Ascona}

San Bernardo da Mentone church is located in Ascona village in the municipality of Santo Stefano d'Aveto (Genova province). Built between 1827 and 1837, the church is the only building in the surroundings with a Greek cross plan. The church, which is $19 \mathrm{~m}$ long and 15 $m$ wide, consists of a single nave with presbytery and semicircular apse. The bell-tower and the canonical house are placed against the presbytery on the left and right side, respectively. The nave is covered by a central sail vault surrounded by 4 lateral barrel vaults with lunettes. The presbytery is covered by a barrel vault with lunettes, while the apse presents an umbrella vault.

San Bernardo da Mentone church is located in a steep area characterized by an average slope angle of $20^{\circ}$. In particular, the church is situated along the right flank (as viewed from the 
crown) of an active landslide classified as complex (Figure 4a). As shown in Figure 4b, the direction of the landslide movement is parallel to the longitudinal axis of the church.

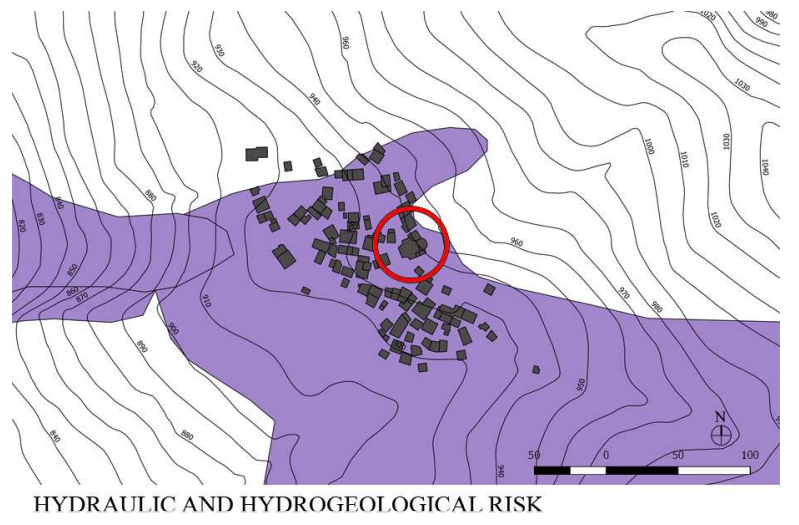

Active landslides

a)

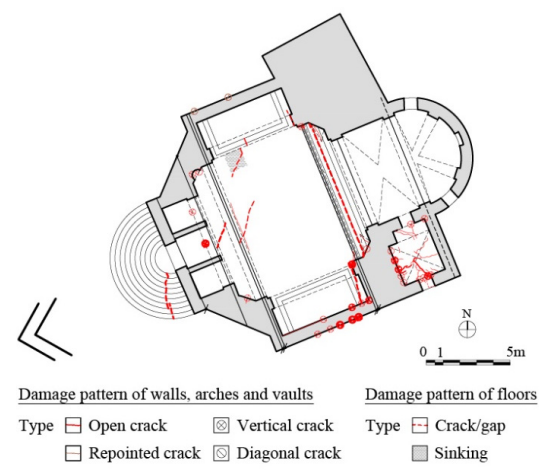

b)

Figure 4: San Bernardo da Mentone church in Ascona: a) position on landslide maps, b) damage pattern.

The crack pattern observed in San Bernardo da Mentone church is depicted in Figure 4b. Both longitudinal walls present large diagonal cracks extending from the ground level and propagating upwards towards the façade (Figure 5a). A large gap crosses transversally the entire floor at the intersection

propagates between the also detected in the floo

and vaults of the canonity
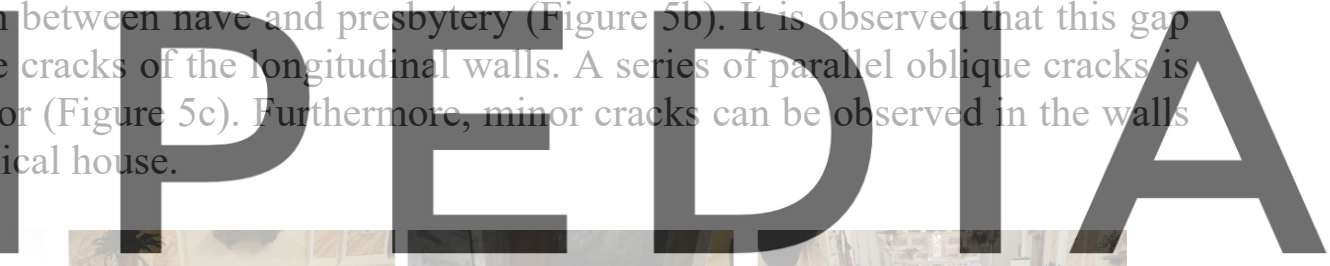

Register for free at https//www.scipedia.com to

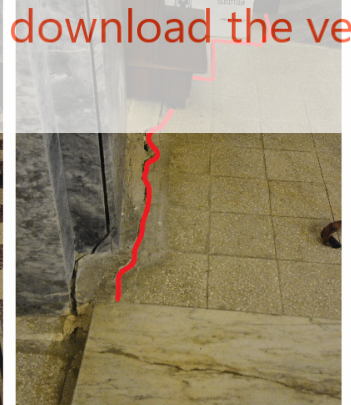

b)

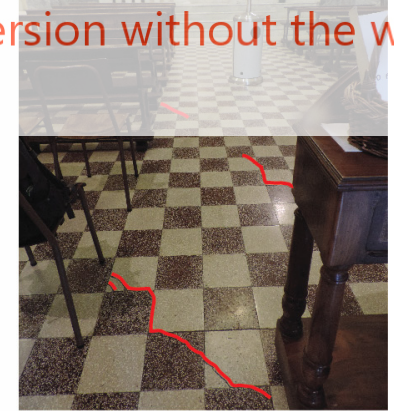

c)

Figure 5: Damage observed in San Bernardo da Mentone church in Ascona: a) diagonal cracks in longitudinal walls, b) large gap/crack in the floor, c) parallel oblique cracks in the floor.

The diagonal cracks occurring in the longitudinal walls at both sides of the church suggest that the building suffered a shear deformation due to differential vertical ground movements in the direction of the longitudinal axis of the church. On the other hand, the large separation among tiles present in the floor at the intersection between nave and presbytery indicates the presence of horizontal displacements. Since both components of ground movements are 
present, it can be assumed that the damage observed in the building was produced by the landslide acting in the area. In this respect, it can also be observed that the crack pattern is congruent with landslide direction since cracks occur in planes orthogonal to the slope movement. It is important to point out that the significant slope of the area where the church is located can contribute to the presence of both vertical and horizontal soil displacements of significant magnitude.

The crack pattern observed in the church also suggests the presence of a separation between the nave and the presbytery. This can be associated either to a different response of the two parts of the building to soil displacements or to the presence of soil discontinuities, which can produce localized differential ground movements when triggered by landslide phenomena.

\subsection{San Lorenzo church in Sorbolo}

San Lorenzo church is located in the village of Sorbolo in the municipality of Follo (La Spezia province). The construction of the church dates back to the end of the seventeenth century. The church, which is $25 \mathrm{~m}$ long and $9 \mathrm{~m}$ wide, consists of a single nave, terminating in an almost squared apse, and a sacristy. The access to the sacristy is possible through a corridor conneeted to the apse area. A bell-tower is located on the left side of the façade. The nave is covered by a barrel vault with lunettes, while the apse presents an umbrella vault. The sacristy and the corridor are covered by a pavilion vault and a barrel vault, respectively. In the last decades the church was subjected to some structural interventions aimed to strengthen the produced by slope movements and worsened by floods. The floor was also refurbished.

San Lorenzo church is located on a steep s.ope characterized by an average \$lope $24^{\circ}$. In particular, the church stands on a terrace bounded to

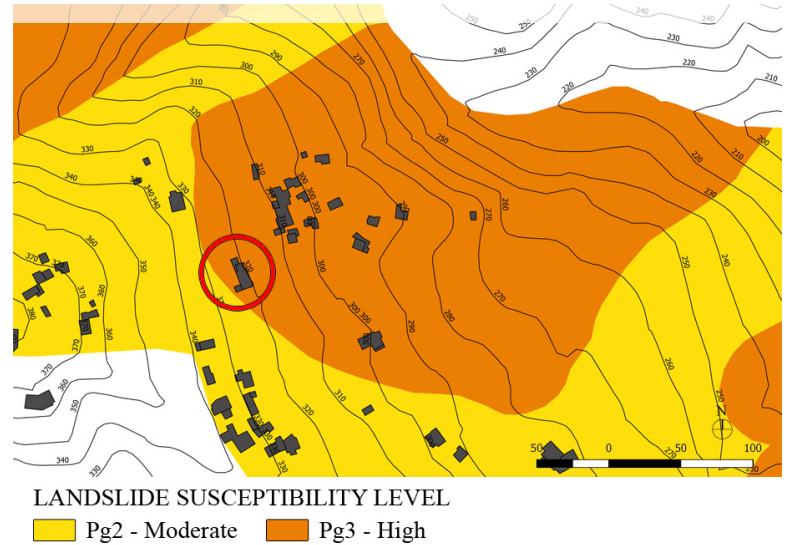

a)

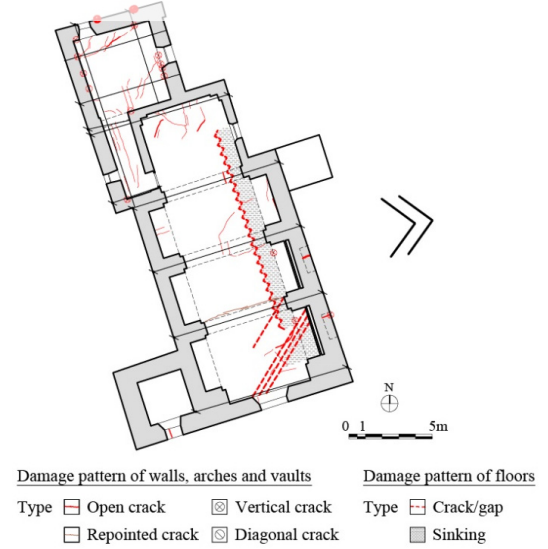

b)

Figure 6: San Lorenzo church in Sorbolo: a) position on landslide maps, b) damage pattern. 
The crack survey of San Lorenzo church is depicted in Figure 6b. It is important to point out that the authors reported the damage currently visible in walls and vaults, while the damage of floor, which was refurbished, was reconstructed thanks to some pictures dating back to 1994. The floor presented extensive damage in the form of gaps among tiles and sinking. In particular, close to the right longitudinal wall, the floor was affected by a saw-tooth gap extending longitudinally over almost the entire length of the nave and presbytery (Figure 7a). In that area, a significant sinking of the floor could also be observed. Furthermore, multiple parallel oblique gaps accompanied by sinking were noticed in the floor of the first bay behind the façade. Damage of walls is localized in the sacristy, which exhibits two large cracks in the north external wall. Regarding vaults, only few minor open cracks can be observed in both the nave and sacristy.

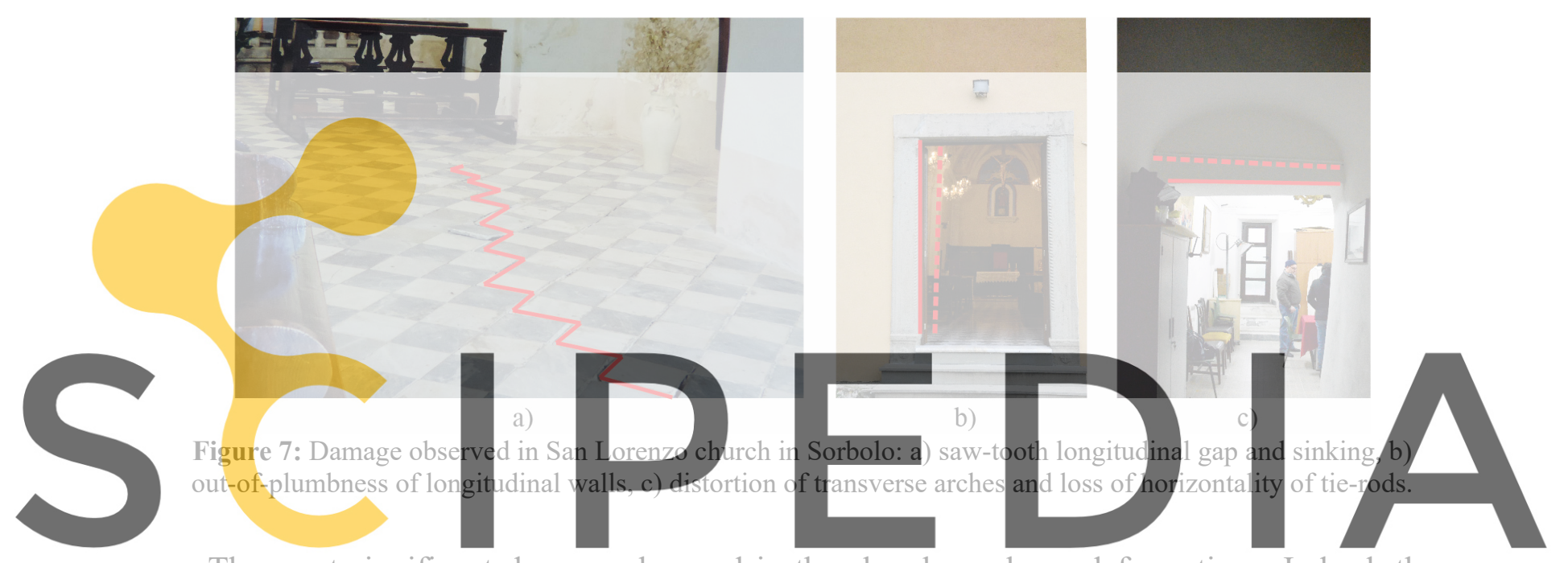

The most significant damage observed in the church are large deformations. Indeed, the

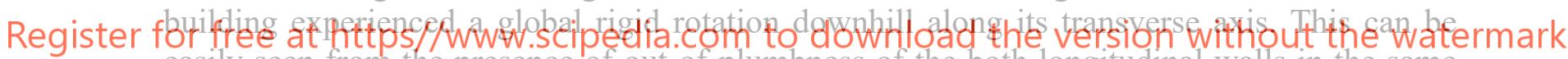
easily seen from the presence of out-of-plumbness of the both longitudinal walls in the same direction (Figure 7b), distortion of transverse arches (Figure 7c) and loss of horizontality of tierods (Figure 7c). These deformations as well as the sinking of the floor on the downstream side of the church suggest that the building was subjected to incremental vertical ground movements in the direction of the transverse axis of the church. Such movements can be reasonably attributed to the landslide acting in the area since the latter is oriented parallel to the transverse axis of the building. Furthermore, such a global mechanism affecting the whole church can hardly be attributed to local subsidence or foundation settlements, which usually produce more localized damage in historical structures. Conversely, slow-moving landslides are associated to large mass movements that can affect the church in its entirety.

Finally, the horizontal separation between tiles observed in the floor indicates that there is also a component of horizontal movement, which is always present in the case of a landslide.

\subsection{Santa Margherita church in Diano Arentino}

Santa Margherita church is located in the municipality of Diano Arentino (Imperia province). The church is currently closed since it was declared not usable due to the severe damage exhibited. The church was built in the fifteenth century above the remains of a pre-existing 
church. Several structural changes were performed over the centuries: in particular, the two lateral domes, the pronaos and the right bell-tower were added later. The church is $30 \mathrm{~m}$ large and $17 \mathrm{~m}$ wide. The plan consists of three naves with lateral chapels, presbytery, semicircular apse and two sacristies. The façade has a pronaos consisting of a giant colonnade and two corner towers. The central nave and lateral naves are covered by cross vaults; the transept presents three octagonal domes; the apse is covered by an umbrella vault and the sacristies present wattle pavilion vaults.

Santa Margherita church is located on slope characterized by an average slope angle of $17^{\circ}$. The church is situated on a large active rotational and translational landslide with an area of 23.4 hectares (Figure 8a). From the maps of the Atlante [13], it can be observed that in the surroundings of the church the landslide direction is almost perpendicular to the longitudinal axis of the church (Figure $8 b$ ).

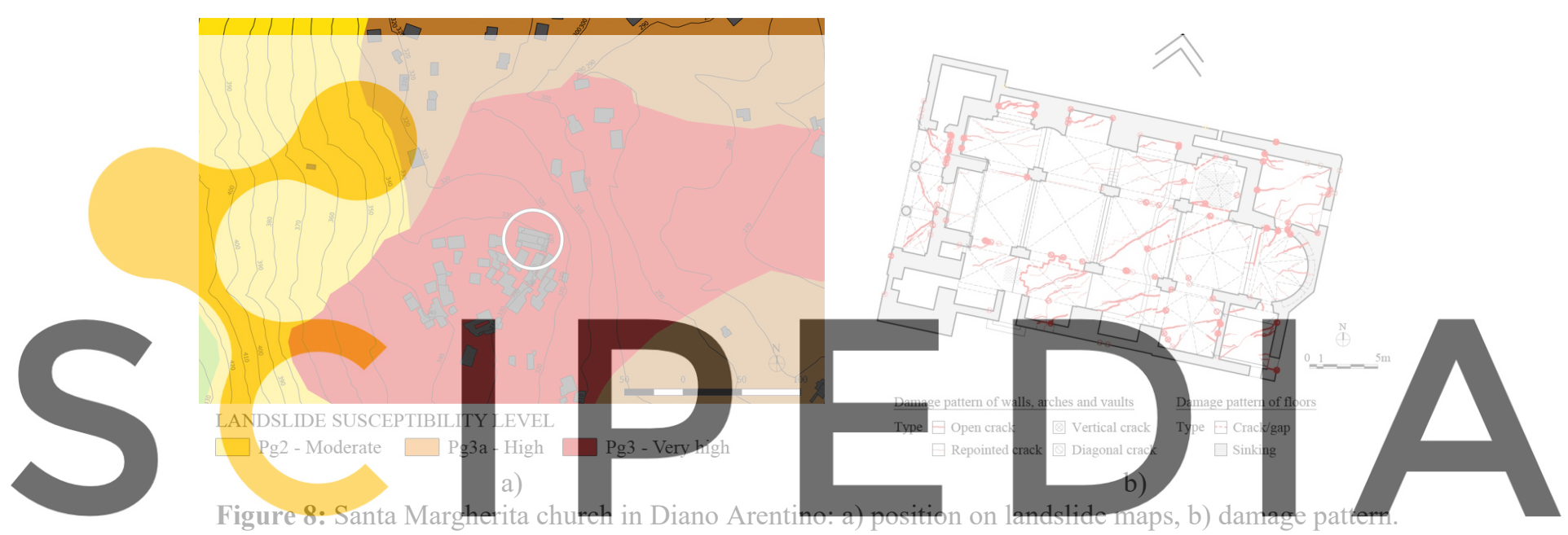

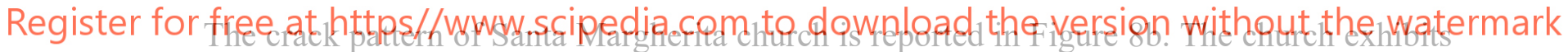
extensive and severe damage. The floor presents a series of parallel oblique gaps affecting both the central nave and the lateral naves. Such gaps are very large, reaching a width of some centimeters (Figure 9a). Moderate to severe damage can be observed throughout the vaults. In particular, the vaults of the central nave, lateral naves, sacristies, apse as well as the right lateral dome of the transept exhibit diagonal shear cracks (Figure 9b), all oriented in the same direction and parallel to the gaps of the floor (Figure 8b). Cracks are also visible in the transverse arches at mid-span. Severe vertical cracks can be observed in the lateral walls as well as in left side of the façade wall. These cracks progress upwards from the level of the ground and cut the structure over its entire height, continuing up into vaults (Figure 9c).

Comparing the crack pattern surveyed with landslide direction, it can be observed that vaults and floor present cracks oriented almost perpendicular to the direction of the slope movement (a certain discrepancy is obviously acceptable since the landslide direction indicated in the maps is approximate). Similarly, the cracks in the walls occur in planes perpendicular to the landslide direction. The congruence between damage pattern and landslide direction leads to the conclusion that the slow-moving landslide acting in the area is the cause of the damage experienced by the church. 


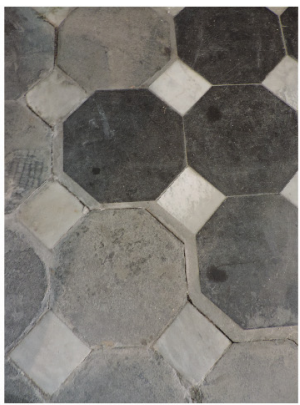

a)

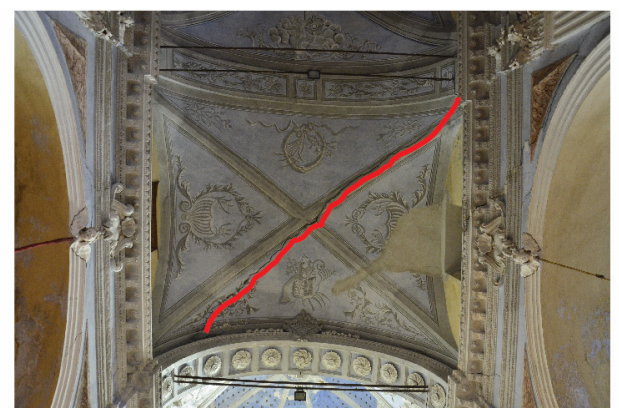

b)

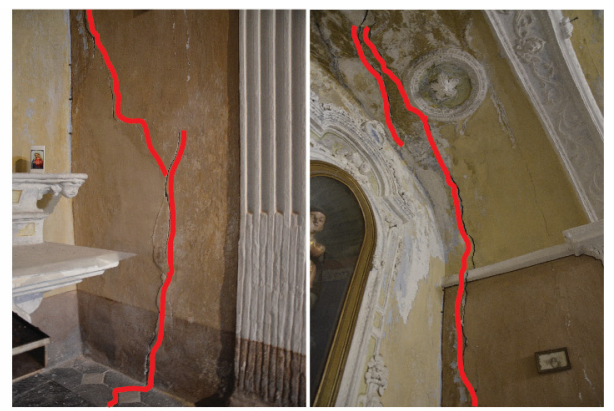

c)

Figure 9: Damage observed in Santa Margherita church in Diano Arentino: a) large gap in the floor, b) diagonal shear cracks of vaults, c) vertical crack progressing over the entire height of the wall from floor to vaults.

Although no information is available regarding the magnitude of the vertical and horizontal components of movement produced by the landslide, the damage pattern observed in the church suggests the presence of a significant component of horizontal displacement. Indeed, the large gaps observed in the floor clearly indicate that tiles moved apart in the horizontal direction. Furthermore, the presence of cracks cutting the structure over the entire height, from floor to vaults, suggests that the church experienced an extension in the landslide direction. The presence of a significant component of horizontal movement again confirms that the damage observed in the church was induced by a landslide. Indeed, phenomena like subsidence or foundation settlements only produce vertical ground movements.

\section{CONCLUSIONS}

This paper discusses the damage mechanisms identified by the authors in historic masonry churches exposed to slow-moving landslide phenomena. Four case studies located in the Liguria region (Italy) in slow-moving landslides-affected areas were investigated. In particular, the damage patterns observed on-site were interpreted in terms of global damage mechanisms and were then correlated with the available information regarding landslide movements. The aim was to demonstrate how each damage mechanism and corresponding damage pattern can be attributed to a specific soil displacement pattern. To this end, firstly the authors assessed the congruence of the damage patterns with estimate landslide direction. This was the first step to attribute the damage observed in the churches to landslide phenomena. Then, cracks and deformations were used to identify the dominant component (horizontal or vertical) of landslide movement. This was necessary since such information was not available from advanced satellite techniques or inclinometers. In particular, the cracks of the floors were found to be good indicators of ground movements. Indeed, sinking and large separations among tiles clearly indicate the presence of vertical and horizontal soil displacements, respectively. As a result, for each of the four churches investigated, it was possible to attribute the damage mechanism to primarily vertical or horizontal ground movements along one of the main axes of the church. In the case of San Martino church in Cembrano, it was interesting to observe how the presence of two landslides acting in different directions in the surrounding area produced a combination of two different damage mechanisms.

In conclusion, this paper provides a first interpretation in terms of global damage mechanisms of the crack patterns and deformations induced to historic masonry churches by 
slow-moving landslides. Future works should include structural analysis to support and verify the assumptions regarding soil displacement patterns made on the basis of visual inspections and crack interpretation.

Acknowledgements. The financial support of PRIN 2015 Program by the Italian Ministry of Education, University and Research (MIUR) is gratefully acknowledged for funding the research project "Protecting the Cultural Heritage from water-soil interaction related threats" (Prot. No. 2015EAM9S5), which is the main framework of the study presented in this article.

\section{REFERENCES}

[1] Ferrero, C., Cambiaggi, L., Vecchiattini, R and Calderini, C. Damage assessment of historic masonry churches exposed to slow-moving landslides. Int. J. Archit. Herit. (2020). In press.

[2] da Porto, F., Silva B., Costa C. and C. Modena. Macro-scale analysis of damage to churches after earthquake in Abruzzo (Italy) on April 6, 2009. J. Earthq. Eng. (2019) 16(6): 739-758.

[3] Lagomarsino, S. and Podestà S. Seismic vulnerability of ancient churches. Part 1: damage assessment and emergency planning. Earthq. Spectra (2004a) 20 (2): 377-394.

[4] Doglioni, F., A. Moretti, and V. Petrini. Le chiese e il terremoto. National Research Council, Trieste, IT: Lint Press (1994) (in Italian).

[5] Saloustros S., Pelà L., Roca p. and J. Portal. Numerical analysis of structural damage in the church of the Poblet Monastery, Eng. Fail. Anal. (2015) 48: 41-61.

[6] Sánchez A. R., Meli R., and Chávez M. M. Structural monitoring of the Mexico City cathedral (1990-2014), Int. J. Archit. Herit (2016) 10 (2-3): 254-6.

[7] Cooper A. H. The classification, recording, databasing and use of information about building damage due to subsidence and landslides. Q. J. Eng. Geol. Hydrogeol. (2008) 41:3.

[8] Cruden, D.M. and Varnes D.J. 1996. Landslide types and processes. In: Landslides: investigation and mitigation, Transportation Research Board, Special Report 247 (1996), pp. 36-75. Washington, D.C.: National Academy of Sciences.

[9] Cascini L., Fornaro G. and D. Peduto Analysis at medium scale of low-resolution DInSAR data in slow-moving landslide-affected areas. ISPRS J. Photogramm. Remote Sens (2009) 64: 598-611

[10] ARPA Piemonte (Agenzia Regionale per la Protezione Ambientale). Linee guida all'interpreazione dei dati satellitari PSInsar ${ }^{\mathrm{TM}}$ in Piemonte (2008).

[11] Piano di Bacino Stralcio per l'Assetto Idrogeologico, Regione Liguria, 2017. Carte della Suscettività al Dissesto (Landslide Susceptibility Maps). Accessed October 25, 2018. http://www.pianidibacino.ambienteinliguria.it/

[12] Piano Stralcio per l'Assetto Idrogeologico, Autorità di bacino distrettuale del fiume Po, 2017. Atlante dei Rischi Idraulici e Idrogeologici (At.las of Hydraulic and Hydrogeological Risks). Accessed October 25, 2018. http://www.pai.adbpo.it/.

[13] Federici, P.R. and Chelli A. Atlante dei Centri Abitati Instabili della Liguria. IV. Provincia di Imperia. Regione Liguria (2007).

[14] MATTM. Geoportale Nazionale. Accessed February 13, 2020. http://www.pcn.minambiente.it/mattm/visualizzatori/ 